Scripta METALLURGICA et MATERIALIA
Vol. 27, pp. 1841-1846, 1992 Printed in the U.S.A.
Pergamon Press Ltd. Al1 rights reserved

\title{
SOME QUESTIONS ON THE STRUCTURE OF MARTENSITE AND PRECURSOR IN
}

Ni $(<63 a t \%)-A 1$ ALLOYS

M. CHANDRASEKARAN ${ }^{*}, J$, BEYER $^{* *}$ and L, DELAEY***

* Universitat de les Illes Balears, Departament de Fisica, Facultat de ciencies, E-07071 Palma de Mallorca, Spain (now at **).

** University of Twente, Faculty of Mechanical Engineering, Laboratory for Materials Science, P.O. Box 217, 7500 AE Enschede, The Netherlands *** Catholic University of Leuven, Department of Metallurgy and Materials Engineering, de Croylaan 2, B-3030 Heverlee, Belgium

(Received September 29,1992 )

(Revised October 19,1992 )

\section{Introduction}

Nickel rich Ni-Al alloys are known to transform martensitically[1-3]. Early reports identified the martensite structure as $L 10$ or $3 \mathrm{R}(1,4-6]$ and the plate substructure as twins [4-6]. Enami et al. [7] reported a softening of the $C$ elastic constant to precede this martensitic transformation in a 63.2 at\% Ni-Al. Subsequently, they reported electron diffraction observations [8] of structural anomalies which they considered preceded the transformation. On the basis of extra spots observed in the patterns they proposed a seven layer, 7R, premartensitic structure. Chandrasekaran and Delaey [9] argued otherwise with results of their own and suggested that the observed pattern was not from a premartensitic, but an already martensitic structure. They further argued that, in spite of the extra spots observed, the martensite could still be considered as a finely twinned $3 R$ phase without the need for invoking separate stacking modulated structures. Soon after, Martynov et al.

[10] again reported $x$-ray diffraction observations of a $7 R$ structure, but considered it as martensitic in a 63.1 at\% $\mathrm{Ni}-\mathrm{Al}$ alloy. It was reported to be the only structure observed in crystals with $a<110>B$ axis when cooled or stressed in tension. But in crystals with a $<100>B$ axis $7 R$ was observed, in tension, to coexist with a predominantly $3 R$ martensite and only in an $X$-shaped region comprising of crossing reliefs, which separated the $B$ phase from the well developed 3R.

Also in the early eighties, Robertson and Wayman, in a sequel to their analysis of tweed in B Ni-Al [11], reported the 7R phase [12] to be observed in thin foils of 63 at\% $\mathrm{Ni}-\mathrm{Al}$ either bulk quenched or aged in situ in TEM at temperatures between $300{ }^{\circ} \mathrm{C}$ and $600{ }^{\circ} \mathrm{C}$. According to these authors, while the tweed microstructure and $\langle 110\rangle \beta$ streaking in the diffraction patterns is a bulk effect, the appearance of extra spots resembling the $7 R$ structure and a part of the diffuse intensity is a thin foil artefact and related to surface transformations similar to those established in $\mathrm{Cu}-\mathrm{Zn}-\mathrm{Al}$ alloys [13]. In the late eighties, and more recently, a number of reports [14-18] based on HREM and neutron scattering studies consider $7 R$ to be the martensitic structure in Ni-Al alloys with nickel contents less than 63 at\%. A possible precursor for this martensite has also been identified in these investigations, which is characterised by $1 / 6 \quad 110$ satellites flanking the $B$ Bragg reflections. Neither Robertson and Wayman's work [12] on possible surface transformations nor our earlier results and arguments [9] to retain the $3 \mathrm{R}$ as the martensitic phase in Ni-Al with substructural twins, has been taken up for discussion in the more recent literature. The present write up is an attempt to show the relevance of these earlier publications to the results and interpretations concerning the proposed martensite and the precursor structure in $\mathrm{Ni}-\mathrm{Al}$. 


\section{Results and Discussion}

The data we present here were obtained from splat cooled or solid state quenched martensitic or partially martensitic samples with compositions from 62 to 65 at\% $\mathrm{Ni}[9,29]$. A common feature, often observed in these samples, is the inhomogeneous distribution of twins, within a martensite plate as seen in fig.1. The very high density of twins concentrated into a band like region is to be noted in this figure. The diffraction pattern from defect free regions, figs. $2 a \& 2 b$, corresponds to that from a Llo/3R structure. On the other hand, the diffraction pattern from a highly defected region could be of varying appearance, as shown in figs. 3a-c. The characteristics observed in these patterns must be attributed not. only to the fineness of the twins but also whether or not they are regularly distributed. A periodic distribution would give rise to the more periodic patterns shown in figs. $3 a$ and $b$, which are suggestive of 7 and 10 layer stacked structures. In less periodically or aperiodically distributed cases, distorted $3 R$ twin type patterns accompanied by profuse streaking along the twin axis can be expected, as shown in the example in fig. $3 \mathrm{c}$. But what needs to be emphasised is that both types of distributions are encountered in the same sample, and tne matrix:twin thickness ratio is around $2: 1$ as is generally characteristic of martensites.

The highly twinned regions just described could have formed where most required to accommodate stresses. With the seemingly easy formation of twins in $3 R$ martensite, such bunching of fine twins may not be an uncommon occurrence as one approaches the $B$-martensite interface or habit plane. Alternately, an entire variant region with a high twin density may also at times be seen, typically when observing samples along $<001>B$ zone axis orientation. These regions could have formed within an existing martensite plate in response to stresses during the transformation. They are associated with a meandering boundary (fig.4) separating it from the main plate variant where the twin planes are derived from the conjugate $\{110\}$ B planes.

It could well be that the low nickel Ni-Al martensites are associated with a higher density of twins. This and the lower Ms temperatures of such alloys is in keeping with the general trend observed in other martensitically transforming alloys as well. In Cu-Zn alloys, for example, the Ms decreases as zinc concentration increases towards the 50-50 composition and the martensites are associated with increasing stacking fault density [19-22]. Such behaviour has been attributed to the so called orthorhombic distortion of the martensite which depends upon the atomic order in $B$ and which has been shown to increase with the zinc content. A similar pattern emerges in the Ni-Al system as well. The ideal undistorted martensite in this case would be fcc. As the aluminium content increases the martensite would be more and more tetragonally distorted, with c/a deviating from unity, and would be associated, as in copper base alloys, with increasing substructure density which is twinning in this case.

We turn our attention next to the HREM of the B phase and the precursor structure (1618]. If the indication by Robertson and Wayman [12] that surface transformations in $B$ foils could give rise to $7 R-1$ ike diffraction effects is taken into consideration, one starts to worry about the interpretation of the HREM images seeking to identify the precursor structure. This is because the thinned foils would then be made up of a martensite/B/martensite sandwich in the relatively thicker regions which merges into a totally martensitic region at the thin edges. HREM images from areas comprising both phases could indeed be complex and appear modulated and distorted. Unless one realises the two phase origin of such images, one coud be misled into believing that it corresponds to a precursor structure developing in $B$. Surface transformations could be driven by changes in composition and influenced by stresses accompanying the formation of an oxide layer or changes in order. While oxidation studies in Ni-Al by Hutchings et al. [23] indicate a suboxide layer which is nickel rich, Reynaud [24] has drawn attention to the possibility of ordering changes towards a $\mathrm{Ni}_{2} \mathrm{Al}$ composition. Both these phenomena could lead to nickel rich Ni-Al layers near the surface raising the $\mathrm{Ms}$ and a possibility of transformation to martensite much as in $\mathrm{Cu}-\mathrm{Zn}-\mathrm{Al}$ 
Fig. 1. Inhomogeneous distribution of twins within a plate of martensite.
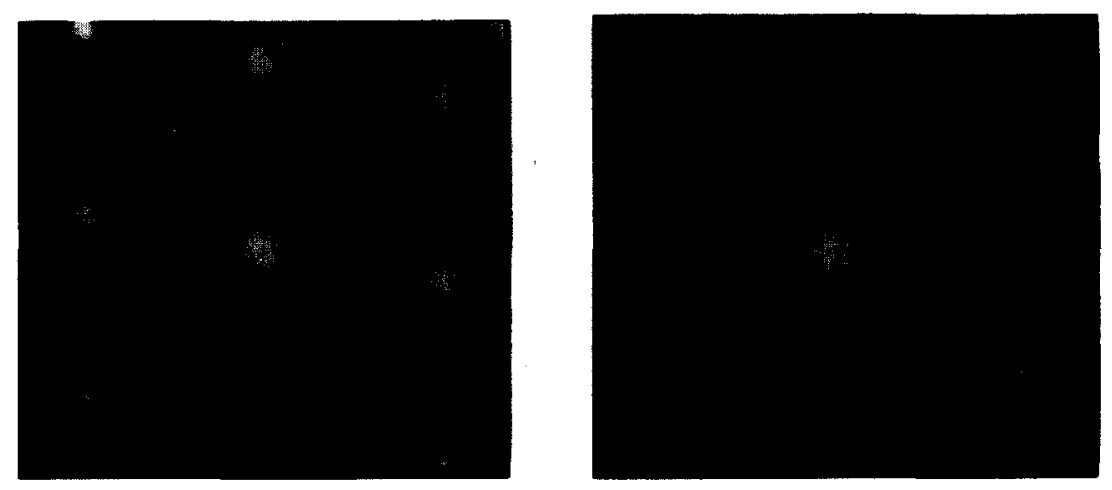

Fig. 2. Diffraction from defect free regions (a) [1i0] L1o zone axis and (b) [0ĩ1] Llo zone axis. 

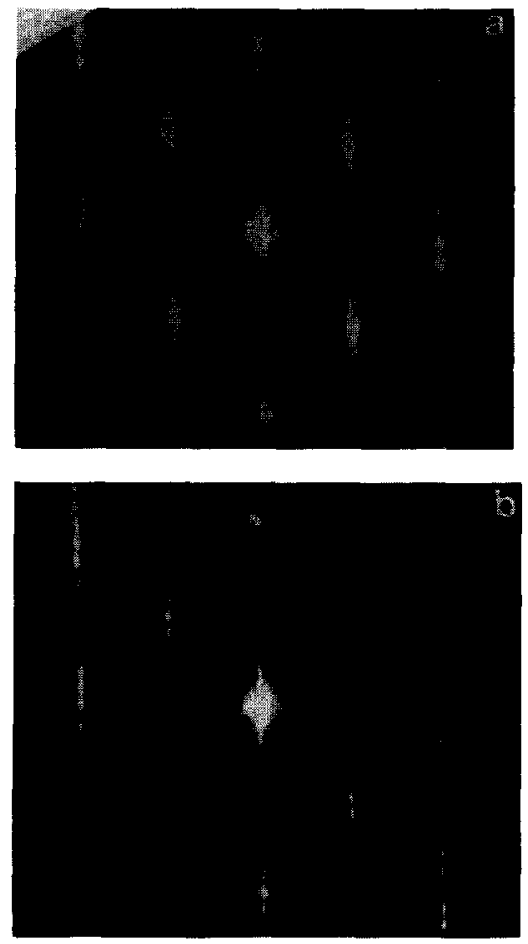

Fig. 3. Diffraction patterns from highly defected reglons.

(a) and (b) periodic distribution of twins.

(c) aperiodic distribution of twins.

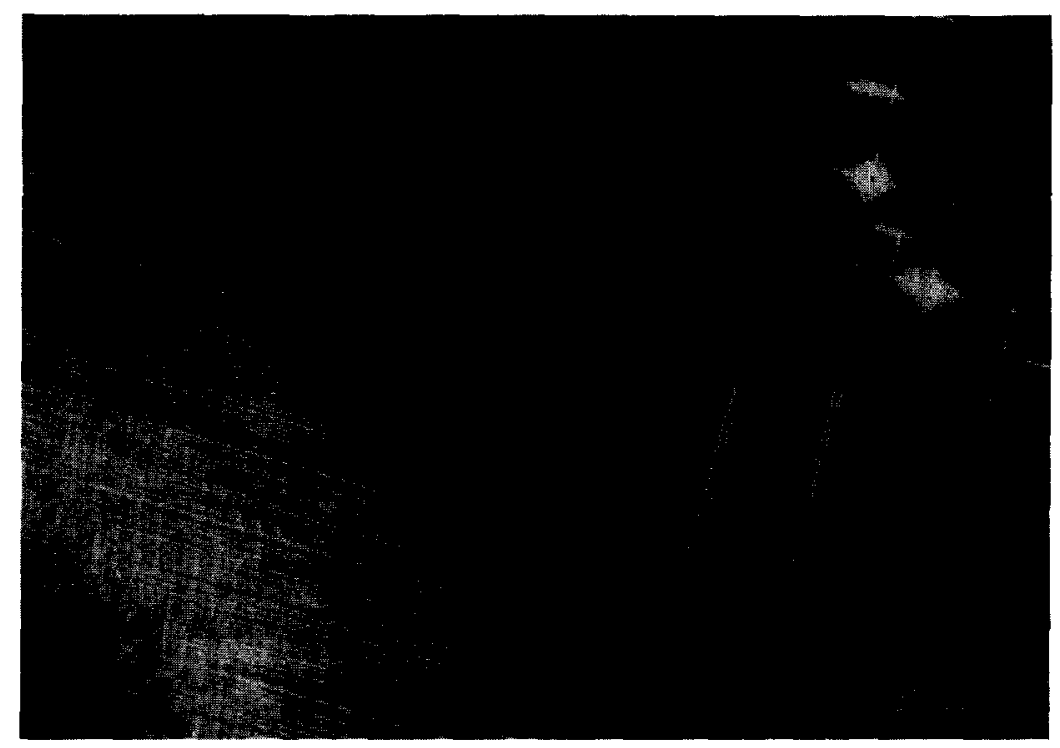

Fig. 4. Meandering interface between variants when electron beam is oriented along [110] Llo zone axis. 
alloys [25]. Surface martensites in these latter alloys are known to be associated with varying fault density, depending on foll orientation, which have been recognised by the accompanying changes in the diffraction patterns $[26,27]$. Systematic work to check whether thinned foils of BNI-A1 are associated with surface transformation will be worth the effort.

In many $x$-ray and electron microscopic investigations $[10,16-18] 7 R$ has been considered as a distinct martensitic phase with an associated possible precursor. It has been shown in this report how stress effects and how surface transformations, if they influence the microstructure, can affect such an interpretation. Another possible explanation of the results taking these factors into account would be that the martensite in N1-Al alloys originates as a twinned $3 R$ phase. As it starts to grow and the high tetragonal distortion of the martensite, habit plane requirements and stresses become important, further twinning occurs in the martensite. In some cases, when the twin density not only increases but the twins are spaced periodically as well, complex diffraction effects resembling those from long period layer structures may be observed. One might ask how this fits in with the reported neutron scattering observations and interpretations. In this regard it has been reported [28] that the position of the dip in the phonon dispersion curve may or may not coincide with that of the final martensite structure as is the case, respectively, for $9 R$ and $2 \mathrm{H}$ martensites in copper base alloys. Further, it would be interesting to know whether the dip in the phonon dispersion curve and the satellites in the elastic scattering flanking the B Bragg reflections, both of which occur around the $1 / 6110$ positions, are observed along all $<110>B$ directions in the reciprocal space as would be expected of a precursor. If they are observed along not all, but specific directions only, could they be construed as due to the presence of already transformed, albeit small, regions of 3R? The assumption of $3 R$ stems from the belief that $1 / 6110$ satellites could be equally representative of $3 R$ structure.

\section{References}

1. S. Rosen and J.A. Goebel, Trans. TMS - AIME, 242, 722 (1968)

2. Y.K. Au and C.M. Wayman, Scipta Met., 6, 1209 (1972)

3. J.S. Smialek and R.F. Heheman, Metall. Trans., 4, 1591 (1973)

4. K. Enami, S. Nenno and K. Shimizu, Trans. JIM, 14, 161 (1973)

5. M. Chandrasekaran and K. Mukherjee, Matls. Sci. Engg., 14, 97 (1974) 6. S.Chakravorty and C.M. Wayman, Metall. Trans. 7A, 555 (1976); 7A, 569 (1976)

7. K. Enami, S. Hasunuma, A. Nagasawa and S.Nenno, Scripta Met., 10, 876 (1976)

8. K. Enami, A. Nagasawa and S. Nenno, Scripta Met., 12, 223 (1978)

9. M. Chandrasekaran and L. Delaey, J. De Physique, C4 43, 661 (1982)10. V.V. Martynov, K. Enami, L.G. Khandros, S. Nenno and A. Tkachenko, Phys. Met. Metall, , 55, 136 (1983)

11. I.M. Robertson and C.M. Wayman, Phil. Mag. A48, 421 (1983); A48, 443 (1983)

12. I.M. Robertson and C.M. Wayman, Metall. Trans. 15A, 1353 (1984)

13. L. Delaey, G. Van Tendeloo, J, Van Landuyt and Y. Murakami, Proc. Int1, Conf. Martensitic Transformations, Cambridge, U.S.A., 1979, pp. 520

14. S.M. Shapiro, J.Z. Larese, Y. Noda, S.C. Moss and L.E. Tanner, Phys. Rev. Lett. 57, 3199 (1986)

15. S.M. Shapiro, B.X. Yang, G. Shirane, Y. Noda and L.E. Tanner, Phys. Rev. Lett., 62, 1298 (1989)

16. D. Schryvers, L.E. Tanner and S. Shapiro in Shape Memory Materials, eds. K. Otsuka and K. Shimizu (Mater. Res. Soc. Proc. 9, Tokyo, 1989) pp. 35

17. L.E. Tanner, D. Schryvers and S. Shapiro, Matls. Sci. Engg., A127, 205 (1990)

18. L.E. Tanner, A.R. Pelton, G. Van Tendeloo, D. Schryvers and M.E. Wall, Scripta Met. and Matla. 24, 1731 (1990)

19. L. Delaey and H. Warlimont, Z. Metallkde. 57, 793 (1966)

20. L. Delaey and I. Cornelis, Acta Met., 18, 1061 (1970)

21. M. Ahlers, Scripta Met., 8, 213 (1974)

22. M. Ahlers, 2. Metallkde., 70, 379 (1979)

23. R. Hutchings, M.H. Loretto and R.E. Smallman, Metal Sci. J., 15, 7 (1981)

24. F. Reynaud, Scripta Met., 11, 765 (1977) 
25. F.C. Lovey, J. Ferron, L.S. de Bernardez and M. Ahlers, Scripta Met., 17, 501 (1983)

26. F.C. Lovey, M. Chandrasekaran, R. Rapacioli and M. Ahlers, Z. Metallkde. 71,37 (1980)

27. F.C.Lovey, M. Chandrasekaran and M. Ahlers, Z. Meta11kde. 72, 43 (1981)

28. A. Nagasawa in Proc. of the Intl. Conf. on Martensitic Transformations, Nara, Japan (1986) pp. 95

29. J.H. Maas, L. Toth, A.A.H. Hamers and J. Beyer, to appear in Proc. of the European Conf. on Martensitic Transformation and Shape Memory Properties, Aussois, France (1991). 